\title{
Brand endorsement by celebrities impacts towards customer satisfaction
}

\author{
C.S. Jayanthi Prasad \\ School of Management Studies, Jaya Prakash Narayan College of Engineering, Mahabubnagar. \\ Accepted 3 January, 2012
}

\begin{abstract}
In India today, the use of celebrity for advertising in companies has become a trend and a perceived winning formula of corporate image-building and product marketing. This phenomenon is reflected in the recent market research finding that 8 out of $10 \mathrm{TV}$ commercials scoring the highest recall were those with celebrity appearances. Today 'celebrity endorsement' has attracted immense debate on whether it really contributes to the brand building process or whether it is just another tool to make the brand more visible in the minds of the consumers. For example, with the Cadbury's worm issue, the brand wanted to build a trust amongst the customers in order to regain its market share. They chose Amitabh Bachchan as an endorser to build that trust and in order to regain their market share. According to the sales data, it was found out that the right celebrity selection gave the right results to them. Firms invest huge amounts as advertising expenditure for hiring the right celebrity. However, there lies uncertainty with respect to the returns that the company might be able to garner for the brand. For example, the Bachchans were endorsing Maruti Versa but this campaign, in spite of the Bachchans being there, was a failure and indirectly the brand was a failure. The consumers were not able to accept the fact that Amitabh Bachchan could ever drive a B-segment car. From the above examples, it can be stated that there should be a synergy between the brand and the endorser. The issue of matching the values of the celebrity with the brand values is also very important, that is, getting the right celebrity to endorse the right brand. Consumers perceive the brand as having superior quality because it has been endorsed by a credible source. This makes endorsement as one of the indictors of quality for any brand. If the celebrity is involved in multiple endorsements, it tends to create confusion among consumers and hence negatively affects the perception of the advertisement and the brand. Hence, to say clearly whether the practice of celebrity endorsement impacts positively or negatively to the brand still remains a debate.
\end{abstract}

Key words: Celebrity, advertising, customer, endorsement.

\section{INTRODUCTION}

\section{Customer satisfaction}

There exists an interaction between the desired results and customer satisfaction, customer loyalty and customer retention. They may go by other names such as patients, clients, buyers, etc. Without the customer it is impossible for any business to sustain itself. Achieving the desired results is frequently a result of customer actions. Any business without a focus on customer satisfaction is at the mercy of the market. Without loyal customers eventually, a competitor will satisfy those desires and your customer retention rate will decrease. Here are some ways to involve the business with the community.

There are several levels of customers:

1. Dissatisfied customer--Looking for someone else to provide product or service.

2. Satisfied customer --- Open to the next better 
opportunity.

3. Loyal customer-returns to the same stores despite offers by the competitors and ready to switch over.

Celebrity endorsement is expensive. Yet the companies are willing to pay for the powerful endorsement embedded in the celebrities whose name, face and/or voice recognition can draw considerable attention of millions of consumers.

Agrawal and Kamakura (1995) estimate that approximately $20 \%$ of all advertisements use some form of celebrity endorsement to inform and persuade. In 2001, IEG Endorsement Insider, an advertising trade publiccation, estimated that celebrities directly received more than $\$ 800$ million in 2001. Celebrities come and go, and their fame may fluctuate as well. However, there are always some celebrities available from entertainment and sports. Some past and present successful celebrity endorsers used over the years include:

\section{LITERATURE}

In order to examine the effect on consumer behavior of the use of a celebrity endorser in advertisements, there are four areas of the literature that must be examined; two areas in the economics literature and two others in the marketing literature. From the economic perspective, the study examined (1) the concept of variable quality and how it is used to differentiate products, and (2) the research that has been done concerning the function of advertising as providing information to consumers. From the marketing perspective, two areas refer to: (1) the research concerning the effect that advertising has on consumers' behavior, and (2) the various effects that are generated by celebrity endorsers in advertising.

\section{Multiple brand and celebrity endorsement}

Studying TV and print advertisements, one will realize that either some celebrities are endorsing several brands or a specific brand is endorsed by different spokespersons. These concepts are called multiple brand endorsement and multiple celebrity endorsement respecttively. Some spokespersons are "shared" by different advertising firms, that is, they are promoting more than one brand (Tripp et al., 1994). Golf champion Tiger Woods has endorsed American Express, Rolex and Nike. Actress Catherine Zeta-Jones is used by T-Mobile and Elizabeth Arden. James Bond character Pierce Brosnan promotes Omega, BMW and Noreico. Top model and actress Milla Jovovich is a spokesperson for a broad range of brands, including L'Oréal, banana republic, Christian Dior, Calvin Klein and Donna Karan (Figure 1 and Figure 3).

The question is does this special form of celebrity endorsement does affect consumers' brand attitudes? Following Tripp et al. (1994), the endorsement of as many as four products negatively influences the celebrity spokesperson's credibility (that is, expertise and trustworthiness) and likeability. They further add that these effects are independent of the celebrity, that is, the perceptions of even well-liked stars can be influenced. Reasons may be found in the lack of distinctiveness, with one famous person endorsing several products instead of concentrating on and representing one specific brand. Though these findings may be valid, it does not automatically mean that the concept of multiple product endorsement is useless. Further research is suggested on potential positive effects, like transfer of positive brand images, and on the shape of consumers' response when more than four products are endorsed.

More satisfying results have been achieved on the concept of multiple celebrity endorsement. Hsu and McDonald (2002) studying the effectiveness of the 'milk mustache campaign' on consumer perceptions, found that endorsing a product with multiple celebrities "can be beneficial for appealing to various audiences to which the product is aimed." The watch manufacturer Omega, for example, promotes its brand by matching selected celebrities with the company's product lines (Figure 2). With celebrity spokespersons representing a diverse mix of type, gender, and age, they can effectively be used to endorse specific brand lines of a company as shown by the cosmetic manufacturer L'Oréal, which matches its diverse product lines in accordance with the celebrity's meanings.

\section{How celebrity endorsements influence the consumer}

The basis for the effectiveness of celebrity-endorsed advertisement can be linked to Kelman's processes of social influence as discussed by Friedman and Friedman. According to Kelman, there are three processes of social influence, which result in an individual adopting the attitude advocated by the communicator (Figure 4).

\section{Compliance, identification and internalization}

Compliance infers that another individual or group of individuals influences an individual because he or she hopes to achieve a favourable reaction from this other group. This process of social influence is not directly applicable to celebrity advertisement because there is little, if any, interaction between the celebrity and the consumer.

Identification applies to the situation wherein the individuals emulate the attitudes or behaviour of another person or group, simply because they aspire to be like that person or group. This process is the basis for referent power. It was found that celebrities are more commonly liked than a typical consumer spokesperson. Internalization as a process of social influence is said to occur when individuals adopt the attitude or behaviour of 
Personalities from Film Industry drives TV ad volumes
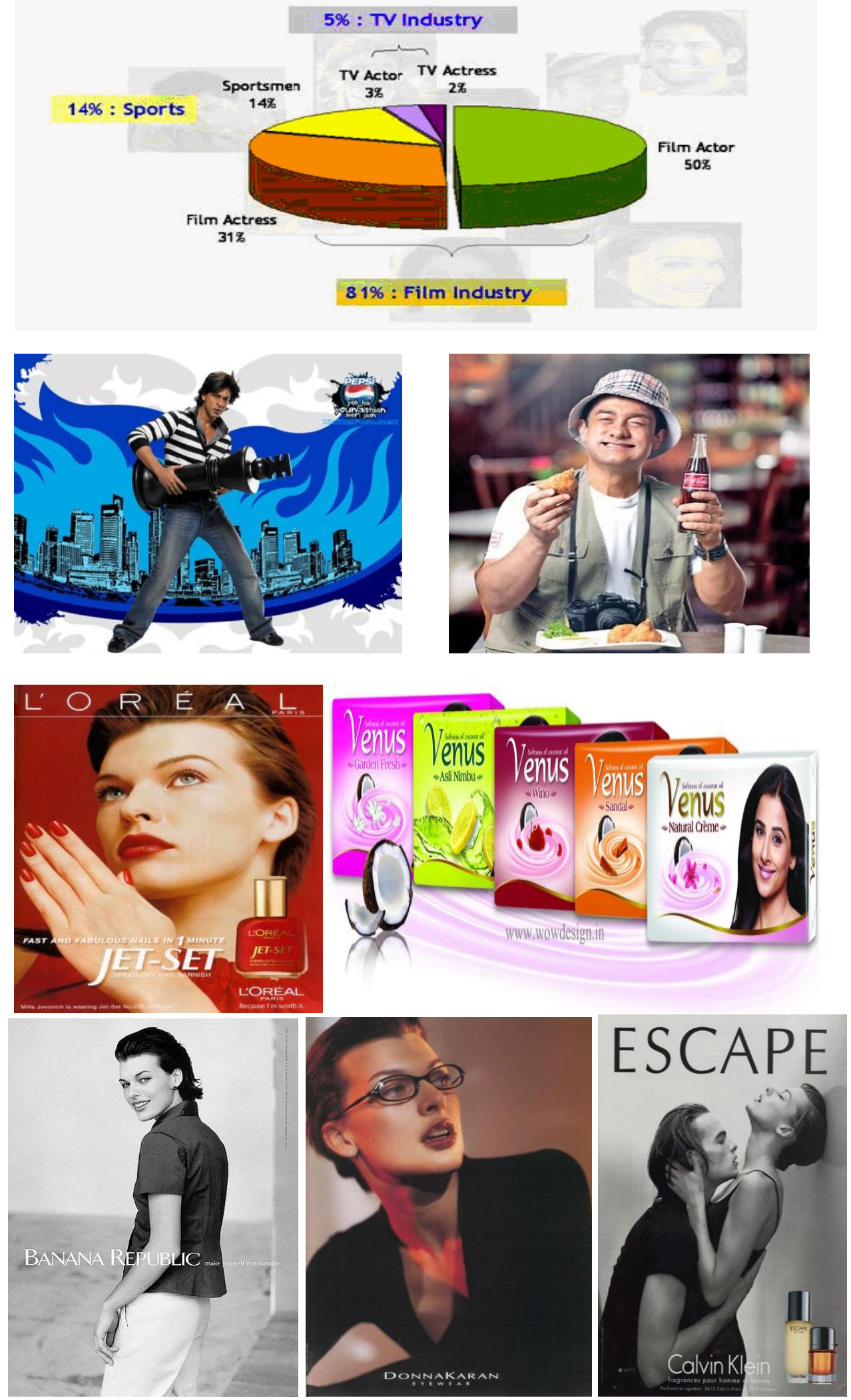

Figure 1. Brands endorsed by top model and actress Milla Jovovich (Source: millaj.com). 

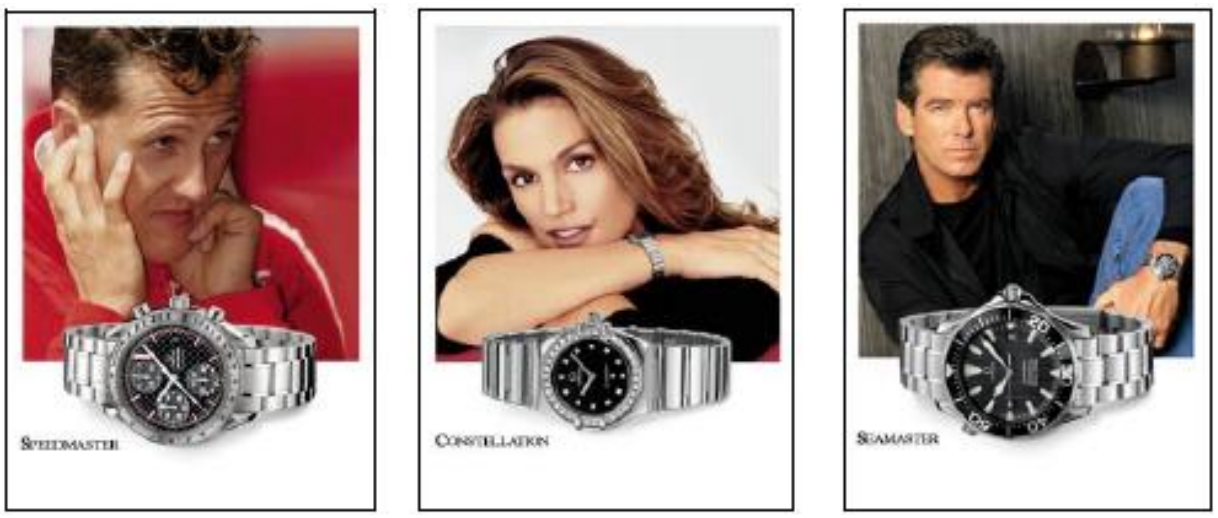

Figure 2. Celebrities endorsing the luxury brand 'Omega'

Source: http://www.omega.ch/omega/wo_star_ambass_entry.

another person because that behaviour is viewed as honest and sincere and is congruent with their value system. The effectiveness of celebrity advertising traditionally has not been strongly linked to this process, as a celebrity's reason for promoting a product can just as easily be attributed by the consumer to an external motive (that is, payment of fee) as to an internal motive (that is, the celebrity's true belief in the value and benefit of the product). An important issue of concern relates to the development of a strategy for use in celebrity advertisement, which benefits from the dramatic impact of dual support of both the identification and internalization processes of social influence. Celebrities are wellliked, but the techniques that can be used to enhance their credibility as spokespeople, and therefore, tie-in more closely with the internalization process needs to be looked into.

\section{METHODOLOGY AND DATABASE}

The experimental data will be used to develop the hypotheses. Using a nine point semantic scale, each subject will be asked to do the following: (1) to rate the attributes, (2) to rate the quality of the product based on the direct and indirect information found in the ad, (3) to rate their impression of the performance of each attribute of the product, (4) to rate respectively how credible and relevant they believe the information to be, and (5) to offer the price they are willing to pay for the product.

The analysis of the data was used to determine if differences exist between treatments, with each treatment representing a different endorser/product combination. The data were also used to develop correlations between the impression of each attribute and the perception of quality. There are six different ads in six different questionnaires each of the two products paired respectively, with; 1) a properly matched endorser, 2) a mismatched endorser, and 3) no endorser. This represents six different treatments utilizing a $3 \times 2$ complete factorial experiment. However, before data were collected, some pre-testing was done in order to determine the appropriate products, celebrity endorsers and attributes. Two pretests are needed. One will be used to determine which celebrities to use in the experiment and what attributes are associated with each celebrity endorser. This information will be utilized to match the

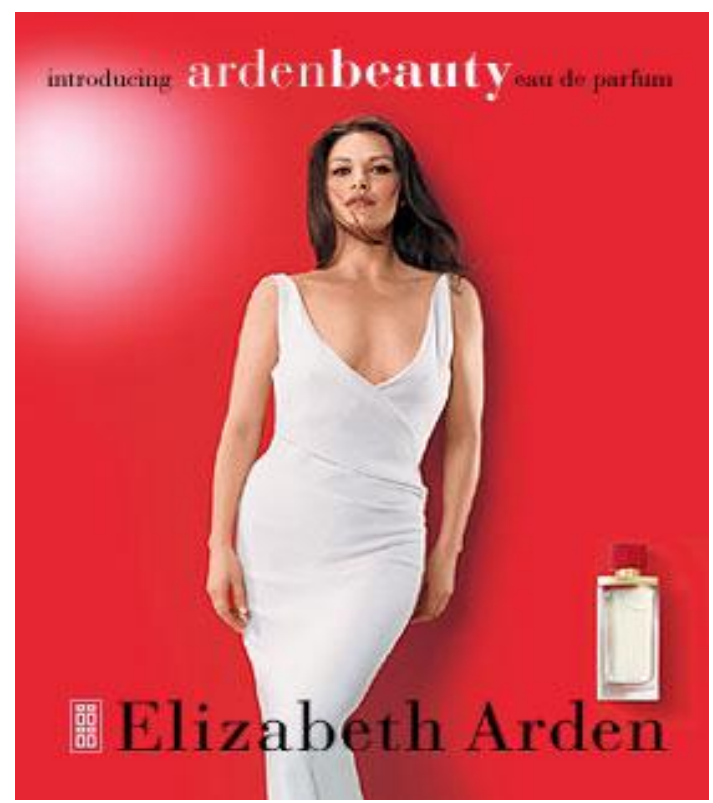

Figure 3. Catherine Zeta-Jones endorsing the brand 'Elizabeth Arden' (Source: elizabetharden.com).

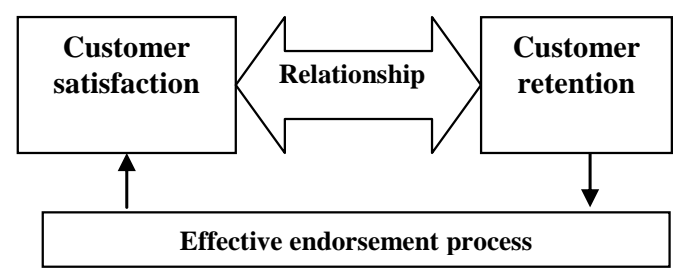

Figure 4. Model of satisfaction-retention relationship through effective endorsement process.

celebrity's attributes to the product attributes in the ad. The second pre-test is used to identify the products that exhibit the same attributes associated with the celebrity endorser determined in the first pre-test. 


\section{Celebrity endorsement has little influence on decisions to buy}

Though companies often scramble to have the most popular celebrities endorse their products, a study reveals that while a celebrity endorsement may enhance the brand recall of a product, it does not for the most part influence the customer's decision to buy. The study conducted by IPAN-IMRB surveyed males and females within the 16 to 45 age-bands in SEC B and C. The study was conducted across the four metros (Mumbai, Delhi, Kolkata and Chennai) and a sample of mid-sized (Indore, Lucknow and Chennai) and small-sized (Ajmer, Madurai, Ranchi, Mahbubnagar and Cuttack) cities.

Eighty-six per cent of the respondents said that the most prominent ad they remembered had a celebrity in it, but only $3 \%$ felt that the celebrity endorser affected their buying decision. According to an official statement, even in the South where celebrities are revered, $58 \%$ said they may remember an ad because of the presence of a celebrity but only $2 \%$ considered the celebrities while buying the product.

\section{Quality, price uppermost}

For the major chunk of $84 \%$ of respondents in South India, qualities followed by price were the most important factors taken into consideration while making a decision to buy. Though, the presence of a celebrity was considered a major reason for an ad to be prominent, only about $24 \%$ of respondents in the South said a celebrity endorsement affected their decisions.

On an all-India basis, $78 \%$ of the respondents felt that 'quality of the product' was the most important factor while buying a product, whereas, only $3 \%$ considered celebrity as an important factor.

The survey reveals that celebrity endorsements help in breaking the clutter. However, with most ads having celebrities; differentiating between the ads was becoming more difficult. More than 8 out of 10 people said that the most prominent ad they remembered today has a celebrity in it; however, there was a clutter in celebrity endorsement.

\section{Brand ambassadors}

Shah Rukh Khan is the most recalled brand ambassador for $17 \%$ of the masses, followed by Amitabh Bachchan (enjoying brand recall by $10 \%)$. Aishwarya Rai topped among female celebrities, enjoying recall among $6 \%$ of the sample size.

\section{Celebrity}

Celebrities are people who enjoy public recognition and mostly they are the experts of their respective fields having wider influence in public life and societal domain. Attributes like attractiveness, extraordinary life style or special skills, larger than life image and demigod status can be associated with them. Celebrities appear in public in different ways. To start, they appear in public when fulfilling their professional commitments, for example: Mahendra Singh Dhoni, who played cricket in front of an audience in T20 world cup. Furthermore, celebrities appear in public by attending special celebrity events, for example: movie award nights; special screening; world premiers of movies or for social causes. These celebrities have universal presence and appeal, they are present everywhere, in news, fashion shows and magazines and above all advertisements.

Celebrity branding is a type of branding, or advertising, in which a celebrity uses his or her status in society to promote a product, service or charity (Figure 1). Celebrity branding can take several different forms, from a celebrity simply appearing in advertisements for a product, service or charity, to a celebrity attending public relations (PR) events, creating his or her own line of products or services, and/or using his or her name as a brand. The most popular forms of celebrity brand lines are for clothing and perfume. Most singers, models and film stars now have at least one licensed product or service which bears their name.

More recently, advertisers have begun attempting to quantify and qualify the use of celebrities in their marketing campaigns by evaluating their awareness, appeal and relevance to a brand's image and the celebrity's influence on consumer buying behavior.

In India from late 1970's and early80's the new trend in advertising started. Brands started being endorsed by celebrities. Hindi film and TV stars as well as sports persons were roped to endorse prominent brands. Advertisements featuring stars like Late Jalal Agha (Pan Parag), Tabassum (Prestige Cookers), Sunil Gavaskar for Dinesh Suitings, Ravi Shastri and Vivan Richards (Vimal), Persis Khambhata and Kapil Dev (Palmolive Shaving Cream) became common.

\section{Celebrities as spokespersons}

Companies frequently use spokespersons to deliver their advertising message and convince consumers of their brands (Figure 1). A widely used and very popular type of spokesperson is the celebrity endorser (Tom et al., 1992). According to Friedman and Friedman (1979) a "celebrity endorser is an individual who is known by the public (...) for his or her achievements in areas other than that of the product class endorsed." The cosmetics manufacturer Elizabeth Arden, for example, uses the actress Catherine Zeta-Jones to endorse its perfume (Figure 3). The reason for using celebrities as spokespersons goes back to their huge potential influence. Compared to other endorser types, famous people achieve a higher degree of attention and recall. They increase awareness of a company's advertising, create positive feelings towards brands and are perceived by consumers as more entertaining (Solomon, 2002). Using a celebrity in advertising is therefore likely to positively affect consumers' brand attitudes and purchase intentions. To ensure positive results, however, it is critical for advertisers to have a clear understanding of the "black box' of celebrity endorsement. In the following section, selected concepts that have to be considered when using celebrities as spokespersons are discussed.

\section{Celebrity endorsement}

Celebrity endorsements give a brand a touch of glamour, and the hope that a famous face will provide added appeal and name recognition in a crowded market (Figure 1). A piece of research states that the target audience age group of 15 to 30 gets influenced first by cricketers, then Bollywood stars and only then music, festival and food. There are around 130 television channels in India broadcasting over 3 million television commercials each year in India. Moreover, people forget $80 \%$ of the information in just $24 \mathrm{~h}$. At some point in the 1980s, Indian marketers found the solution, which is 'Celebrity Endorsement' for the brand!

Firms endorse celebrity for a variety of reasons; firms invest significant money in putting together brands and organizations with endorser qualities such as attractiveness, likeability and trustworthiness.

\section{Conclusions}

The conclusions from this study can be used to explain why basketball shoes endorsed by Michael Jordan, a 
known expert basketball player, will be priced at a level up to $100 \%$ higher than similar shoes sold at the same location. It also explains why name brand products are priced at a large premium above the generic brands which are physically the same. The consumers perceive the endorsed or name brand to be of higher quality and are therefore willing to pay more. It appears that the selection of an endorser who is viewed positively by consumers and who is known to possess attributes which match up with the attributes of the product, is critical in order for the indirect information to significantly impact the consumer's perception. Mismatched endorsers or endorsers who are not viewed positively will have a much smaller impact on consumers.

On the other hand, an endorser who may not match up perfectly with the product, but who is viewed positively may still have an effect on the consumer, although the effect will probably be smaller than with a properly matched endorser. Well liked endorsers can have positive effects on consumer perceptions even if they do not match up well with the product.

When one endorser endorses many brands, then the recall of the endorsement depends entirely on the power of the brand. There are definitely some brands that go unnoticed and the recall for those stands is at a bare minimum. The company in that case can heighten the advertising content because that etches a special place in the mind space of the consumer.

\section{REFERENCE}

Aaker DA (1996). Building Strong Brands. New York, NY: The Free Press. AdEX India (A Division of TAM Media Research).

Alycia de Mesa "Sell-lebrity: Products Get Star Treatment", brandchannel.com.

Daneshvary R, Keith SR (2000). "The Association Endorsement and Consumers' Intention to Purchase," J. Consum. Market., 17(3):203213.

Erdogan BZ (1999). "Celebrity Endorsement: A Literature Review", J. Market. Res., 15:291-314.

Friedman HH, Linda F (1979). "Endorser Effectiveness by Product Type," J. Advert. Res. 19(5):63-71.

Goldsmith L, Newell SJ (2000). "The Impact of Corporate Credibility and Celebrity Credibility on Consumer Reaction to Advertisements and Brands", J. Advert. 29(3):43-54.

Jayashree M (2008). "Beauties Hog the Endorsement Street", Pitch 5: 12, March 2008, Jayashree Maji, "Beauties Hog the Endorsement Street", Pitch 5(5):13.

Leon BG (provide year). "Everyone's got a perfume and a fashion line. What next for celebrity brands?" leonbaileygreen.com

Maheswaran D, Sternthal B (1990). The effects of knowledge, motivation, and type of message on ad processing and product judgements. J. Consum. Res. 17:66-73.

Tom GC, Elmer R, Greech L, Masetti EJ, Sandhar H (1992). The Use of Created Versus Celebrity Spokesperson in Advertisements. J. Consum. Market., 9(4):45-51.

Tripp C, Jensen TD, Carlson L (1994). The Effect of Multiple Product Endorsements by Celebrities on Consumers' Attitudes and Intentions. J. Consum. Res. 20(4):533-547. 